\title{
Recommended Design Modifications and Operational Approaches to Allow Continued Precipitation Operations at Current ITP Facility
}

by

A. Blanchard

Westinghouse Savannah River Company

Savannah River Site

Aiken, South Carolina 29808

J. K. Thomas

WSMS

J. K. Norkus

WSMS

This paper was prepared in connection with work done under the above contract number with the U. S. Department of Energy. By acceptance of this paper, the publisher and/or recipient acknowledges the U. S. Government's right to retain a nonexclusive, royalty-free license in and to any copyright covering this paper, along with the right to reproduce and to authorize others to reproduce all or part of the copyrighted paper. 


\section{DISCLAIMER}

This report was prepared as an account of work sponsored by an agency of the United States Government. Neither the United States Government nor any agency thereof, nor any of their employees, makes any warranty, express or implied, or assumes any legal liability or responsibility for the accuracy, completeness, or usefulness of any information, apparatus, product, or process disclosed, or represents that its use would not infringe privately owned rights. Reference herein to any specific commercial product, process, or service by trade name, trademark, manufacturer, or otherwise does not necessarily constitute or imply its endorsement, recommendation, or favoring by the United States Government or any agency thereof. The views and opinions of authors expressed herein do not necessarily state or reflect those of the United States Government or any agency thereof.

This report has been reproduced directly from the best available copy.

Available to DOE and DOE contractors from the Office of Scientific and Technical Information, P. O. Box 62, Oak Ridge, TN 37831; prices available from (423) 576-8401.

Available to the public from the National Technical Information Service, U. S. Department of Commerce, 5285. Port Royal Road, Springfield, VA 22161. 


\section{DISCLAIMER}

Portions of this document may be illegible in electronic image products. Images are produced from the best available original document. 
WSRC-RP-98-00735

Recommended Design Modifications and Operational Approaches to Allow Continued Precipitation Operations at Current ITP Facility

August, 1998

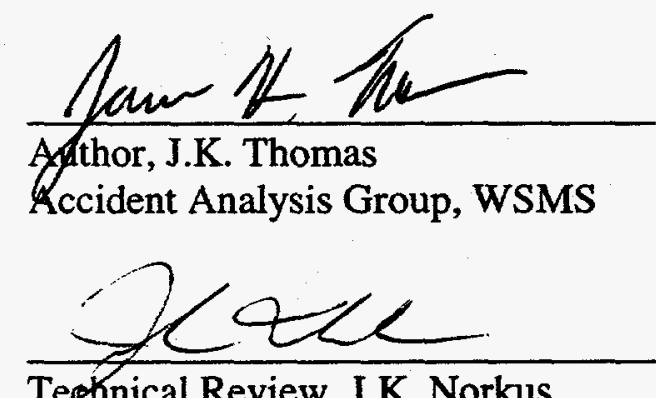

Teennical Review, J.K. Norkus Accident Analysis Group, WSMS

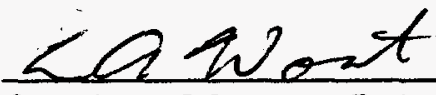

Cognizant Manager, L.A. Wooten Accident Analysis Group, WSMS

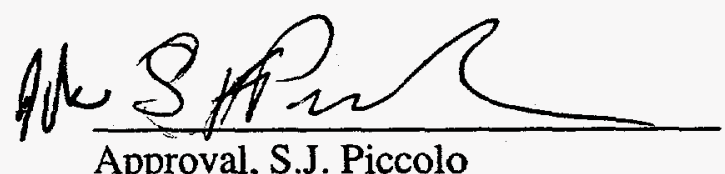

Approval, S.J. Piccolo

HLW Salt Disposition Systems

Engineering Team Leader, WSRC
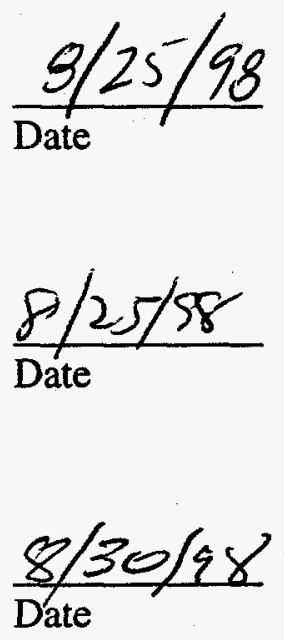

$\frac{9-4-98}{\text { Date }}$

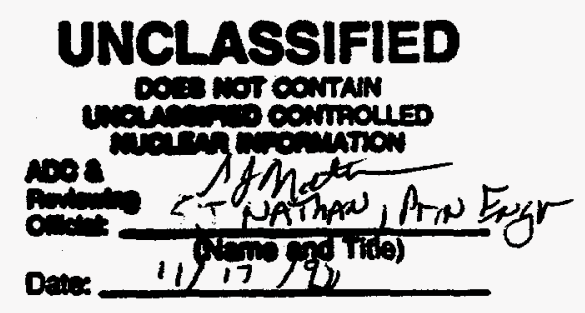




\section{TABLE OF CONTENTS}

1.0 INTRODUCTION

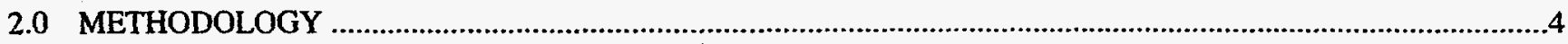

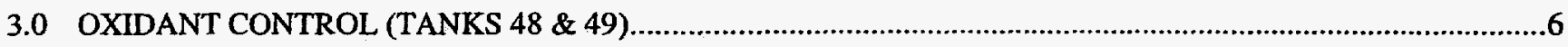

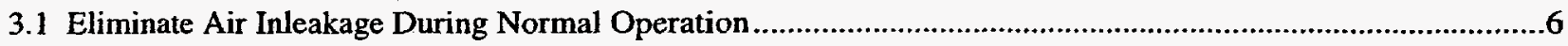

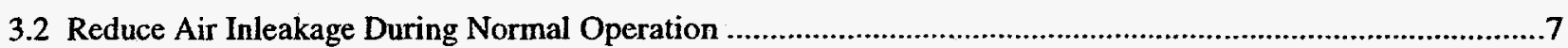

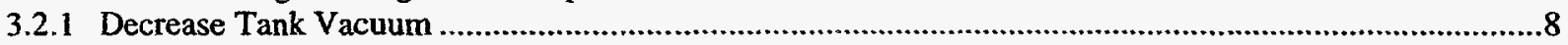

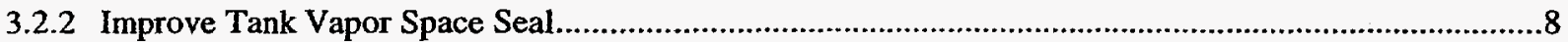

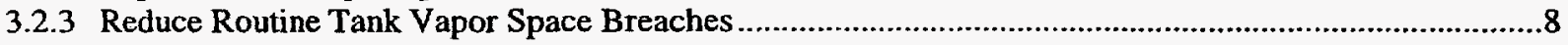

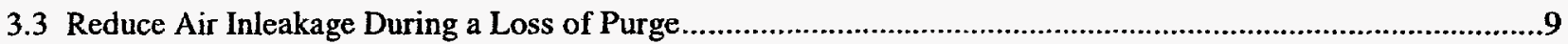

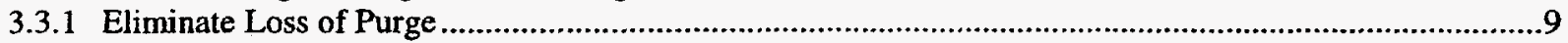

3.3.2 Improve Tank Vapor Space Isolation Upon Loss of Purge .......................................................................

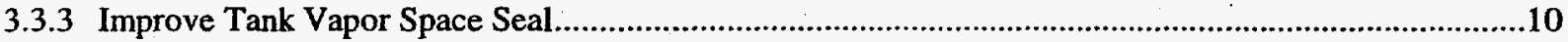

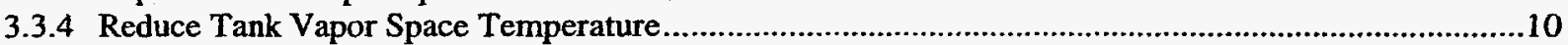

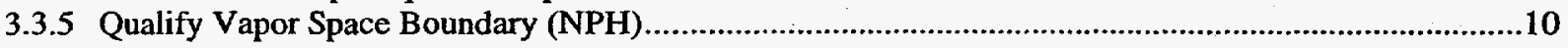

3.4 Improve Performance of Backup Inerting System ........................................................................................

3.5 Decrease Potential for Localized Regions with Elevated Oxygen Concentration ............................................11

3.5.1 Improve Tank Vapor Space Mixing .....................................................................................................12

3.5.2 Improve Tank Vapor Space Measurement Capabilities ...............................................................................12

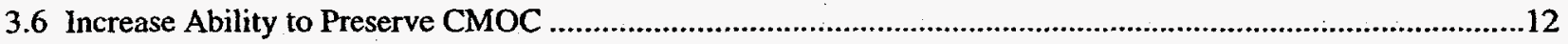

3.6.1 Reduce Oxygen Concentration Below Minimum Possible CMOC ........................................................12

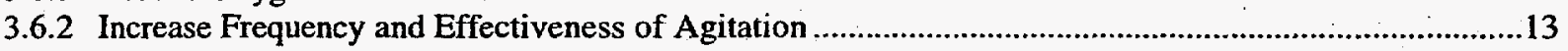

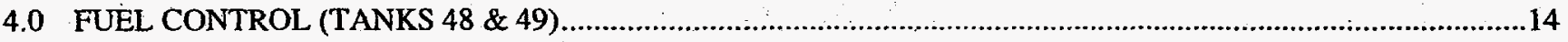

4.1 Reduce Precipitate Decomposition and Benzene Generation Rates .............................................................14

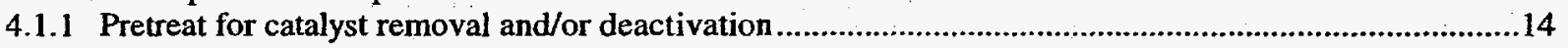

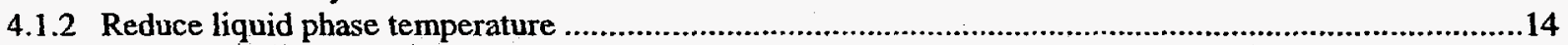

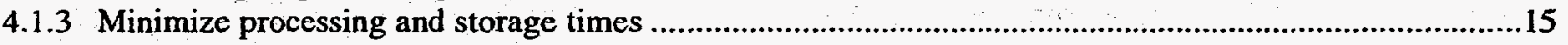

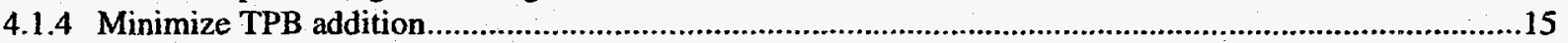

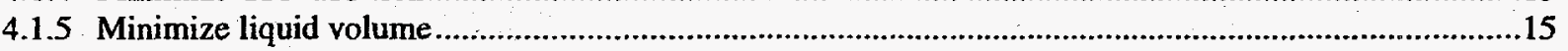

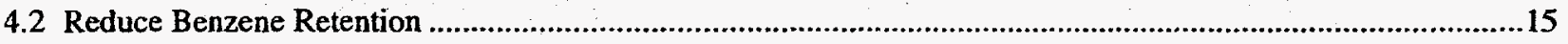

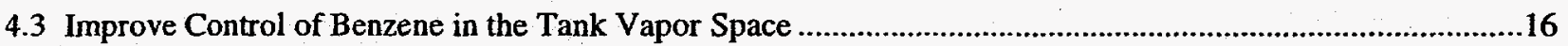

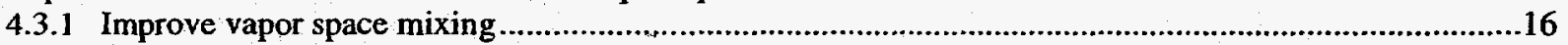

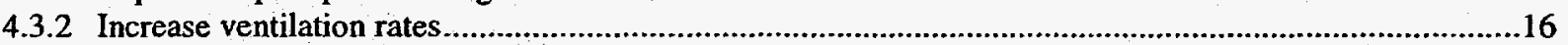

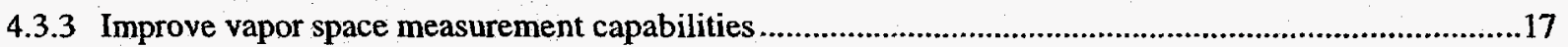

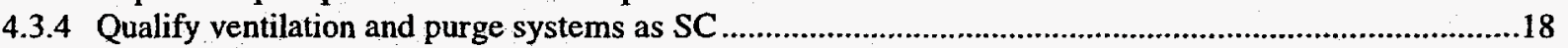

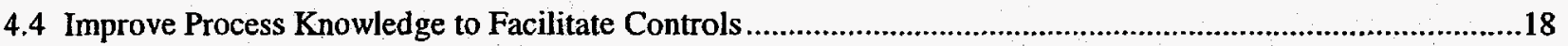

4.4.1 Improve Liquid-Phase Measurement Capabilities ............................................................................18

4.4.2 Improve Vapor-Phase Measurement Capabilities ..................................................................................18

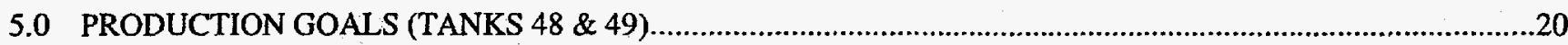

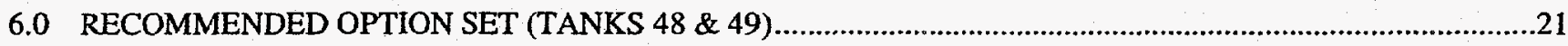

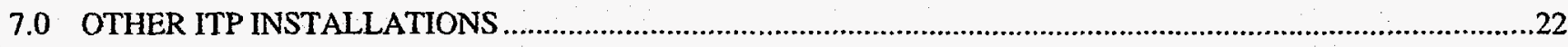

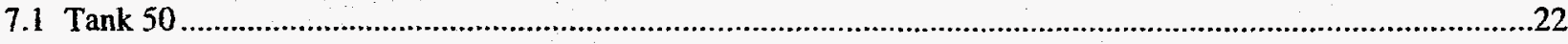

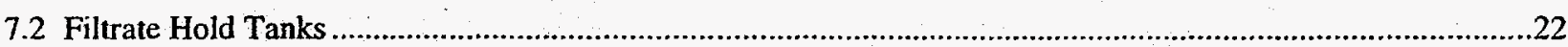

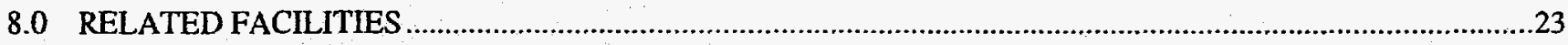

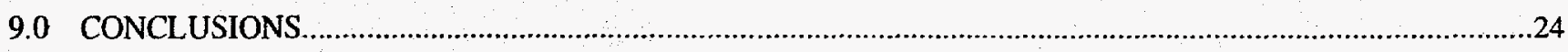

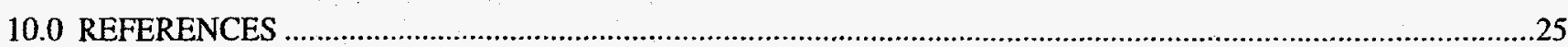




\subsection{INTRODUCTION}

Based on the current understanding of benzene generation, retention, and release mechanisms, WSRC has concluded that the production goals and safety requirements for HLW processing cannot be accomplished in the ITP Facility as currently configured (Whittenburg 1998, Jacobs et al. 1998). The purpose of this report is to provide a set of recommended design modifications and operational approaches that would allow continued precipitation operations at the "current ITP facility". With respect to this evaluation, the current ITP facility is taken to be Tank 48 (precipitation reaction, slurry concentration, and slurry washing), Tank 49 (concentrated slurry storage), the filtrate hold tanks (FHTs), and Tank 50 (spent wash water storage). Other facilities that should be considered with respect to safety issues associated with benzene generation, retention, and release include: Saltstone (receipt of decontaminated filtrate), Late Wash (post-ITP wash and precipitation prior to delivery of slurry to DWPF), and the Low Point Pump Pit (transport of slurry from Late Wash to DWPF Vitrification Facility).

It should be clearly understood that meeting the safety requirements for HLW processing involves more than simply meeting the DOE Evaluation Guidelines. External reviewers must be satisfied that the risk posed by vapor space flammability issues is acceptable. Unfortunately, the term "acceptable risk" is difficult to define precisely. It is, in a very real sense, defined by what level of risk external regulatory authorities will be willing to accept in order to process HLW. As such, the selection of a safety strategy that will result in an "acceptable risk" is very much an exercise in judgement. Similarly, uncertainties in precipitate decomposition kinetic preclude complete assurance that production goals will be met regardless of potential facility modifications. Hence, while it is the judgement of the author that adopting the recommendations provided in this report would provide a high level of assurance that the HLW processing production goals and safety requirements could be met, this outcome is not guaranteed.

Modifying the current ITP facility is only one of many options being considered to meet the production goals and safety requirements for HLW processing. A number of alternative processing options are currently being reviewed that could potentially accomplish these objectives (Whittenburg 1998). The schedule and cost impacts associated with the recommendations provided in this report will serve as a benchmark against which those alternative processing options can be measured.

Note that the intent of this report is to provide relatively broad recommendations. It is expected that, if modifying the current ITP facility was selected as the best option available, then the general recommendations provided in this report would be utilized to develop a set of detailed recommendations, which would then be followed by specific implementation plans.

The safety issues associated with the current ITP facility are related to vapor space flammability. The production goal issues are related to precipitate stability. This evaluation focuses on Tanks 48 and 49 
since the bulk of the risks associated with the vapor space flammability and production goal issues are related to operations in these tanks. Potential required modifications to the other ITP facility installations (Tank 50 and FHTs) are also reviewed, but in much less detail. Potential modifications to associated facilities (Saltstone, Late Wash, and the Low Point Pump Pit) are considered beyond the scope of this work.

Sections 3 and 4 discuss the options available for improved oxidant and fuel control, respectively, in Tanks 48 and 49 . Section 5 discusses the impact of selected fuel control options on production goals. The final set of recommended options for Tanks 48 and 49 is summarized in Section 6 . Section 7 discusses recommended modifications to other ITP facilities. Section 8 reviews the status of these issues relative to related facilities. The conclusions of this evaluation are summarized in Section 9. 


\subsection{METHODOLOGY}

The safety issues associated with the current ITP facility are related to vapor space flammability. These issues are driven primarily by the benzene generation, retention, and release mechanisms. Uncertainties associated with these mechanisms have precluded the development of an operational strategy which would ensure fuel control; that is, it is difficult to ensure that that the combustible gas concentration cannot exceed the Composite Lower Flammability Limit (CLFL) within a significant portion of the tank vapor space. It is assumed for the purposes of this evaluation that no approach would provide complete assurance that the benzene generation, retention, and release mechanisms could be controlled such that fuel control would be a viable flammability control strategy. It is possible that additional experiments may indeed provide a sufficient knowledge base that fuel control could be assured. However, this is not the case at the current time and, based on the judgement of the author, this will not be the case in the foreseeable future. Nevertheless, a viable (i.e. licensable) safety basis will require a high level of fuel control as a defense in depth measure. The safety basis for the current facility also relies on fuel control as a defense in depth measure for most operational phases, so this strategy is not a change in safety basis philosophy. What is required is an increased level of assurance that fuel control can actually be maintained. In addition, there will probably be some major maintenance activities which cannot be conducted with the tank in an inerted mode; fuel control must be assured during such activities. The main goals which could be achieved with respect to fuel control are summarized in Table 1 along with the options considered for each of these goals

Production issues also arise from elevated benzene generation rates, since benzene generation is a direct result of tetraphenylborate (TPB) solids decomposition. The decomposition of TPB solids allows cesium to go back into solution and hence decrease the decontamination factor that can be achieved. Addressing the production issue requires that the TPB decomposition rate, and hence benzene generation rate, be controlled.

Given that a near $100 \%$ confidence fuel control strategy is unavailable, then oxidant control (i.e. inerting) must be assured in order to provide a viable safety basis with respect to vapor space flammability issues. The safety basis for the current facility also relies on inerting as a primary means of flammability control for most operational phases, so this strategy is not a change in safety basis philosophy. What is required is an increased level of assurance that inerting can be maintained. There are two basic inerting strategies that can be employed: positive pressure inerting and negative pressure inerting (where the sign of the pressure indicates the tank vapor space pressure relative to the external environment). Both strategies are considered in this evaluation. However, it should be noted at this point that routine positive pressure inerting would require a secondary confinement system in order to be compatible with radiological contamination and worker safety practices. A negative pressure inerting system, while compatible with radiological contamination and worker safety practices, results in air inleakage into the tank vapor space 
and hence poses a number of design and operational challenges with respect to oxidant control. The current inerting systems employed with Tanks 48 and 49 utilize a negative pressure inerting system for normal operations and a low flow rate positive pressure system as a backup [i.e. the Standby Nitrogen System (SNS)]. The main goals which could be achieved with respect to oxidant control are summarized in Table 2 along with the options considered for each of these goals. Note that many of the options considered for improved fuel control would also serve to improve oxidant control as well.

It is recognized that, in addition to fuel and oxidant control, the risk posed by vapor space flammability issues can be partially mitigated by control of ignition sources. However, as a general safety philosophy, ignition control is a poor primary safety strategy. Therefore, while ignition source control should be vigorously pursued as part of the normal course of risk management, it should not be adopted as a primary safety strategy unless other options are unavailable. Since this is not the case with respect to the current evaluation, ignition source control is not considered further within this report.

The approach adopted in this evaluation was to collect the options available for decreasing the risk posed by vapor space flammability issues and increasing the confidence level that production goals can be met, and then qualitatively rank these options with respect to their potential for meeting these objectives. The most effective options were then selected as the set of recommended design modifications and operational approaches which would allow continued precipitation operations at the current ITP facility. In this context, the determination that an option is "effective" is meant to convey both that the option will be effective in terms of meeting a specific goal and it is expected that the option will be effective in terms of its relative order-of-magnitude cost. As note above, some of the options which would act to improve oxidant control would also improve fuel control, and some of the options which would act to improve fuel control would also improve process viability. The options which contribute simultaneously to improved oxidant control, fuel control, and process viability, have an obvious attraction. 


\subsection{OXIDANT CONTROL (TANKS 48 \& 49)}

Oxidant control must be the primary safety strategy employed to control the risks associated with vapor space flammability, as discussed in Section 2. Table 2 summarized the main goals to improve oxidant control along with the options considered for achieving each of these goals. This section provides a discussion of these goals and, for each goal, the options considered to achieve that goal are presented and discussed in terms of their relative effectiveness. Based on these discussions, a recommendation is made as to the extent to which each option should be pursued.

\subsection{Eliminate Air Inleakage During Normal Operation}

Two approaches are available to achieve the goal of eliminating air inleakage during normal operation: (1) seal the tank perfectly so that a negative tank pressure does not result in inleakage, or (2) operate the tank at a positive pressure. The first approach (perfect seal) is not judged to be achievable and hence this is not a viable option. The second approach (positive pressure) can accomplish the goal of eliminating (or at least minimize) air inleakage, but would result in gas from the tank vapor space flowing out unfiltered leak sites onto the tank top. This is incompatible with normal radiological contamination and worker exposure (radiological, toxicological) controls. Additional concerns would be the potential for asphyxiation due to the local inert gas accumulation and the formation of small flammable gas regions external to the tank. Hence, the tank vapor space flammability risk reduction achieved by positively pressurizing the tank vapor space must be balanced with the increased risk to workers and the environment.

A low flow rate positive pressure system could potentially limit the potential for radiological contamination and exposure to an acceptable level (i.e. by limiting gas velocity in the tank vapor space and through the leak sites). However, the flow rate required to exclude air inleakage at a high confidence level for a period as short as a few weeks would be on the order of at least several hundred cfm (Thomas 1997a), and excluding it entirely is unrealistic. A low flow rate positive pressure system therefore will not exclude air inleakage. Low flow rates could, however, limit air inleakage to the extent required to preserve inerting. For example, Thomas (1997a) concluded that a flow rate of $30 \mathrm{scfm}$ would preserve inerting given the current tank leakage (hydraulic resistance) characteristics; sealing the tank better would lower the required flow rate. However, a low flow rate system would result in very high benzene concentrations, even if the benzene generation rate were limited to that due to radiolysis. High benzene concentrations combined with a positive tank pressure would pose an unacceptable worker toxicological exposure risk. Fuel control would also have to be abandoned as a defense in depth measure with this approach. Furthermore, it is realistic to expect that the benzene concentrations associated with extended low flow rate positive pressure operations would result in the formation of small combustible gas regions external to the tank; it is doubtful that this would be acceptable. Alternatively, a very high flow rate 
system would pose unacceptable environmental contamination, worker radiological exposure and asphyxiation risks.

It should be noted that it might be possible to utilize a low flow rate positive pressure system and avoid high benzene concentrations. This could, in theory, be accomplished by developing and implementing a catalytic benzene destruction system internal to the tank vapor space. Such a system would be required to essentially remove all of the benzene from the inlet stream and return "clean" gas to the tank vapor space. The system would have to handle at least a moderately high flow rate in order to control the toxicological exposure risk to an acceptable level. It is judged unlikely that such a system can be procured. This approach would also require an internal mixing device within the vapor space to provide sufficient driving force to mix the vapor space; if this were not done, then benzene released from the precipitate slurry could potentially stratify at high release rates. Lastly, as noted above, a low flow rate system will not actually preclude air inleakage, only ensure that it is held to an acceptable level.

Based on the arguments presented above, it is clear that a positive pressure inerting system for normal operation would almost certainly require a secondary confinement system. The requirement for a secondary confinement structure is judged to eliminate positive pressure inerting during normal operation as a viable option. Backfitting a secondary confinement structure over the waste tanks (singularly or as a collection) would be prohibitively expensive. It is the judgement of the author that if a secondary confinement structure is viewed as an absolute requirement, then it should be pursued as part of a new ITP replacement facility rather than as an upgrade to the "current ITP facility". It is noted that positive pressure inerting may be compatible with the "small tank ITP" design concept, which is one of the potential design options under consideration as a replacement for the current ITP facility (Whittenburg 1998).

Since neither option of eliminating air inleakage during normal operation is judged to be viable, it is concluded that this goal cannot be achieved.

\subsection{Reduce Air Inleakage During Normal Operation}

Air inleakage cannot be eliminated, as discussed in the preceding section, but it can be significantly reduced. Reducing the air inleakage rate during normal operation would reduce the bulk vapor space oxygen concentration and hence the margin associated with oxidant control. In addition, reducing the normal bulk vapor space oxygen concentration would also improve the margin associated with the response to a loss of purge. The goal of reducing air inleakage during normal negative pressure tank operation can be achieved by:

- decreasing the tank vacuum,

- improving the tank vapor space seal (i.e. increasing the tank hydraulic resistance, and/or

- reducing routine tank vapor space breaches. 
Each of these options is discussed separately below.

\subsubsection{Decrease Tank Vacuum}

The current operational approach employed with Tanks 48 and 49 is to maintain the tank vapor space at a significant vacuum (approximately $1 / 2$ inch water column) in order to ensure that contamination control and worker protection goals are met. With the current Tank 48 hydraulic resistance characteristics, this tank vacuum results in an air inleakage rate of 100 to $150 \mathrm{scfm}$. This vacuum can be reduced, at least slightly, without compromising the contamination control and worker protection. This option should be pursued.

\subsubsection{Improve Tank Vapor Space Seal}

The facility has attempted on numerous occasions to improve the tank seal. These efforts have been successful in that the leak rates through identifiable leakage points have been reduced. However, these efforts have not been a high priority relative to other pressing facility commitments. Further reductions would probably require testing to identify significant leak sites and subsequent redesign of the riser plugs and equipment seals for those sites. It is judged that a coordinated effort, supported by moderate budget, resource, and schedule resource commitments could yield significant improvements. This option should be pursued. Note that this option also would contribute to the goals of reducing air inleakage during a loss of purge and improving the performance of the backup inerting system.

It is judged that combining these two options (vacuum reduction and sealing improvement) could reduce the normal air inleakage rate down to approximately $50 \mathrm{scfm}$. With the current nitrogen purge system, this would cut the bulk vapor space oxygen concentration during normal operation from $6 \%$ (typical for current configuration) down to $3 \%$. As noted above, this would significantly improve the margins associated with inerting during normal operation and with the response to a loss of purge.

\subsubsection{Reduce Routine Tank Vapor Space Breaches}

The $3^{\text {rd }}$ option for accomplishing this goal is to reduce routine tank vapor space breaches. A typical example of such a breach involves the removal of a cover plate on the mixing pump to valve in bearing water to the pump. Similar breaches are occasionally made to facilitate various in-tank measurements. The facility has considered this option in the recent past and proposed some preliminary concepts. It is recommended that these concepts should be pursued.

Hence, it is recommended that all three options (decreasing tank vacuum, improving vapor space seal, and reducing routine tank vapor space breaches) be implemented to maximize the decrease in air inleakage during normal operation. 


\subsection{Reduce Air Inleakage During a Loss of Purge}

This goal concerns the inleakage of air into the tank vapor space following a loss of ventilation and purge. Reducing the air inleakage rate during a loss of purge would increase the time required for the bulk vapor space oxygen concentration to increase from the value associated with normal operation up to the CMOC. As noted in the preceding section, reducing the normal bulk vapor space oxygen concentration would also improve the margin associated with the response to a loss of purge. The goal of reducing air inleakage during a loss of purge can be achieved by:

- eliminating the loss of purge entirely (qualify ventilation and purge systems as SC),

- improving the tank vapor space isolation upon a loss of purge,

- improving the tank vapor space seal (see goal \#2),

- reducing the tank vapor space temperature, and/or

- qualifying the vapor space boundary with respect to NPH events.

Each of these options is discussed separately below.

\subsubsection{Eliminate Loss of Purge}

Precluding a loss of purge would, of course, be the best option to accomplish this goal. This option would require that both the ventilation and purge systems be qualified as Safety Class; these systems would probably have to be replaced almost in their entirety. It is the judgement of the author that this approach, while highly desirable, is not required in order to achieve an acceptable level of risk reduction. It is expected, based on the discussions between facility personnel, DOE, and DNFSB over the past several years, that such an approach would be prohibitively expensive. However, it is recommended that the cost and schedule requirements associated with this option be estimated and compared with the alternative options for achieving this goal. If these requirements are not comparatively severe, then this option should be considered. Note that this option would also have obvious benefits with regards to fuel control.

\subsubsection{Improve Tank Vapor Space Isolation Upon Loss of Purge}

This option would involve ensuring that all engineered tank vapor space penetrations are sealed following a loss of purge. The main penetrations of interest are the normal exhaust ventilation path and the conservation vent bypass valve. An effort had been initiated to procure and install a seismically qualified isolation valve for the normal exhaust ventilation path; this effort should be completed. The conservation vent bypass valve should be left closed during inerted operations. A review of other engineered penetrations should be conducted to ensure they would be closed following a loss of purge.

In addition, NPH qualified interlocks must be in place to ensure that all agitation, transfers, and additions are immediately secured in the event of loss of purge. 


\subsubsection{Improve Tank Vapor Space Seal}

A recommendation to improve the tank vapor space seal was made in the preceding section (3.2) in connection with decreasing air inleakage during normal operations. Reducing air inleakage, and hence the bulk vapor space oxygen concentration during normal operation would increase the amount of air which must be drawn into the tank following a loss of purge in order to reach the CMOC. In addition, improving the tank vapor space seal would decrease the air inleakage rate following a loss of purge, hence increasing the amount of time required to draw in the required amount of air. This option should be pursued.

\subsubsection{Reduce Tank Vapor Space Temperature}

Thomas (1997b) demonstrated that natural convection is the dominant air inleakage mode following a loss of purge. The bounding conditions included the current maximum allowable tank vapor space temperature $\left(40^{\circ} \mathrm{C}\right)$ and a $95^{\text {th }}$ percentile minimum daily temperature $\left(-4^{\circ} \mathrm{C}\right)$. To a first approximation, the natural convection air inleakage rate is proportional to the temperature difference between the tank vapor space and external environment. Hence, decreasing the maximum allowable tank vapor space temperature from $40^{\circ} \mathrm{C}$ to $25^{\circ} \mathrm{C}$ would cut the bounding natural convective air inleakage rate by over $30 \%$ (the total inleakage rate would drop by about 20\%). The time required to raise the bulk vapor space oxygen concentration by a fixed amount is, to a first approximation, proportional to the air inleakage rate. Hence, reducing the allowable tank vapor space temperature to $25^{\circ} \mathrm{C}$ would increase the time required to reach the CMOC following a loss of purge by about $20 \%$. This option should be pursued. It is noted that, as discussed in Section 4.1, this option would also improve process viability and fuel control.

Reducing the allowable tank vapor space temperature down into the range of 20 to $30^{\circ} \mathrm{C}$ would probably require that a chiller system be utilized and that the existing cooling coil system be augmented, repaired, or replaced. The chiller system requirements would also be impacted by the need for increasing the liquid phase agitation frequency and efficiency (see Sections 3.6 and 4.2). It should be noted, as discussed in Section 4.2 , that structural integrity considerations and the need to ensure that solid benzene deposits could not be formed would impose lower limits on the tank temperature.

\subsubsection{Qualify Vapor Space Boundary (NPH)}

An effort had been initiated to seismically qualify all engineered tank vapor space penetrations; this effort should be completed. However, these penetrations were not qualified with respect to tornado damage. Instead, the current facility safety basis is to shut down operations upon a severe weather warning to ensure that the combustible gas concentration would be well below the CLFL. This would provide sufficient time to seal any tank breaches due to tornado damage and re-establish full oxidant control. This strategy is still judged to be acceptable from a risk perspective and highly cost-effective. 


\subsection{Improve Performance of Backup Inerting System}

The performance of the backup inerting system [i.e. the Standby Nitrogen System (SNS)] would obviously be improved by reducing the air inleakage rate during a loss of purge. The options available to accomplish this goal were discussed in the preceding section.

The backup inerting system performance could also be improved by refining the control scheme currently associated with the system. It is recommended that a review of the current control scheme be conducted to identify potential improvements. One specific recommendation in this regard would be to allow the nitrogen flow rate to be decreased after the required maximum flow rate had been established and verified given the presence of vapor space oxygen monitoring capability. The maximum purge flow rate will be well in excess of that required to preserve inerting under all but the most bounding conditions. Allowing the flow rate to be decreased in response to actual conditions would provide the facility the capacity to greatly enhance nitrogen conservation during backup purge system operations.

Improved controls are also recommended to support the transition from the low flow rate positive pressure inerting back to the normal purge and ventilation systems. This will almost certainly dictate that the transition mode be handled automatically, as opposed to requiring operator actions.

In addition, the impact of operation of this system on the rest of the ITP facility must be assessed and accounted for. That is, positive pressure purging in Tank 48 or 49 may lead to elevated benzene levels in the immediate vicinity of these tanks. The control room ventilation system and operator protective equipment must be equipped to account for this. Facility emergency preparedness plans and evacuations procedures must also take this into consideration.

\subsection{Decrease Potential for Localized Regions with Elevated Oxygen Concentration}

This goal concerns the potential for the formation of localized regions of the tank vapor space to have elevated oxygen concentrations even though the bulk oxygen concentration is well below the CMOC. It should be noted that an evaluation of this phenomena has shown that such regions would be very localized (Thomas 1996b). The goal of reducing the potential for and extent of localized regions with elevated oxygen concentration can be achieved by:

- reducing the air inleakage rate,

- improving mixing within the tank vapor space, and/or

- improving the tank vapor monitoring capabilities.

The first option, reducing the air inleakage rate, was discussed in Sections 3.2 and 3.3; the recommendations given in those sections are directly applicable here. The other two options are discussed separately below. 


\subsubsection{Improve Tank Vapor Space Mixing}

It would be, in theory, possible to improve the dissipation of air drawn into the tank by improving mixing within the bulk tank vapor space. However, all evidence from in-tank testing indicates that air drawn into the tank is well-mixed. The same conclusion can be drawn from the tank vapor space mixing CFD (computational fluid dynamics) evaluations that have been carried out to date, although the CFD evaluations were targeted specifically at the mixing behavior of benzene released from the slurry. It is possible that additional CFD evaluations and/or experiments might indicate regions where mixing could be improved. However, since the air inleakage sites are not well characterized, it would not appear likely that such studies could be used to dictate design modifications to the purge system. Hence, no specific recommendations are provided to accomplish this goal with respect to air inleakage.

\subsubsection{Improve Tank Vapor Space Measurement Capabilities}

It is recognized, of course, that improving the capability to measure oxygen concentration distributions in the tank vapor space will not actually improve the mixing behavior of the tank. However, improved measurement capabilities would support more meaningful analysis of the potential for localized regions with elevated oxygen concentrations. The facility had initiated design efforts for a set of two axial sampling arrays to measure both oxygen and benzene concentrations. These design efforts should be completed.

\subsection{Increase Ability to Preserve CMOC}

The current inerting safety strategy is to ensure that the bulk oxygen concentration remains below the CMOC (with some margin). The CMOC is taken to be $9 \%$, which requires that the hydrogen to benzene ratio be controlled (Thomas 1996a). This control is implemented by agitating the slurry via pump operations at a calculated frequency to release retained hydrogen [see, for example, Thomas (1997c)]. At large curie loadings, the required frequency of pump operations could be very high. There are two options of increasing the confidence level associated with the ability to preserve the CMOC value:

- reduce the tank vapor space oxygen concentration below the minimum possible CMOC, and/or

- increase the frequency and efficiency of agitation.

Each of these options is discussed separately below.

\subsubsection{Reduce Oxygen Concentration Below Minimum Possible CMOC}

The minimum CMOC value would be that with hydrogen as the only combustible (slightly less than $5 \%$ ). Given a significant reduction in the air inleakage rates during normal operation and during a loss of purge, it is quite possible that an oxygen concentration below that hydrogen MOC could be ensured; this would be highly desirable. Hence, the recommendations given in Sections 3.2 and 3.3 are directly applicable here and are reiterated. 


\subsubsection{Increase Frequency and Effectiveness of Agitation}

If the first option cannot be achieved with a very high degree of confidence, then it will be necessary to ensure that the mixing pumps can be run with sufficient frequency and effectiveness to preclude an accumulation of hydrogen in the slurry beyond the amount dictated by CMOC preservation. As noted above, high curie loadings would require very frequent pump operations. It is doubtful that the current pumps could be operated over a long period on such a schedule. Furthermore, it is unknown if the current pumps are capable of effectively mixing the slurry with high liquid volumes. This is particularly true if one or more of the pumps must be taken out of service for maintenance. It is therefore recommended that replacement of the current pumps be considered. If, as assumed here, the current pumps cannot effectively mix the slurry under all conditions on a high frequency schedule over an extended period, then they must be replaced with a system that can accomplish this objective. Note that if the vapor space oxygen concentration could be achieved, then this recommendation would be obviated with respect to CMOC control. However, increasing the frequency and effectiveness of agitation is an option for improving fuel control by reducing benzene retention, so this recommendation may have to be implemented even with a significantly reduced vapor space oxygen concentration. 


\subsection{FUEL CONTROL (TANKS 48 \& 49)}

Fuel control must be pursued as a defense in depth safety strategy to control the risks associated with vapor space flammability, as discussed in Section 2. It should be recognized that fuel control will be required as the primary safety strategy during major maintenance activities which require the purge to be taken off-line or compromise the inerting system; this puts additional emphasis on a robust fuel control scheme. Table 1 summarized the main goals to improve fuel control along with the options considered for achieving each of these goals. This section provides a discussion of these goals and, for each goal, the options considered to achieve that goal are presented and discussed in terms of their relative effectiveness. Based on these discussions, a recommendation is made as to the extent to which each option should be pursued.

\subsection{Reduce Precipitate Decomposition and Benzene Generation Rates}

The precipitate decomposition rate must be controlled in order to increase the confidence that HLW processing production goals can be met (i.e. in order to ensure process viability). The benzene generation rate must be controlled as part of the defense in depth fuel control strategy. Five approaches are available to achieve the goal of reducing precipitate decomposition and benzene generation rates:

- Treating the waste prior to TPB addition to remove and/or deactivate the catalyst,

- Reducing the liquid phase temperature,

- Minimizing the processing and storage times,

- Minimizing the amount of TPB added to the tank, and/or

- Minimizing the liquid volume.

Each of these options are discussed separately below.

\subsection{Pretreat for catalyst removal and/or deactivation}

Experimental work performed to date indicates that TPB decomposition is catalyzed by palladium, copper, and sludge components, and that catalytic decomposition is responsible for the majority of the TPB decomposition and benzene production observed in Tank 48 (Jacobs et al. 1998). It is possible to filter the liquid waste prior to TPB addition (pretreatment step) in order to remove solid sludge component. It may be possible to remove the other catalysts by ion exchange processes, or to deactivate these catalysts by the addition of a poison. It is recommended that a pretreatment step be added to remove and/or deactivate the known catalysts. Implementing such an approach would greatly increase the confidence level associated with process viability and fuel control as a defense in depth safety strategy.

\subsubsection{Reduce liquid phase temperature}

Experimental work performed to date indicates that the TPB decomposition rate is greatly reduced at lower temperatures, or at least the onset of the decomposition reaction is significantly delayed (Jacobs et al. 1998). Lowering the maximum allowable liquid temperature to no more than $25^{\circ} \mathrm{C}$ is therefore recommended. It is recognized that this would require that a chiller system be utilized and that the 
existing cooling coil system be augmented, repaired, or replaced. The chiller system requirements would also be impacted by the need for increasing the liquid phase agitation frequency and efficiency (see Sections 3.6 and 4.2). It is noted that structural integrity considerations and the need to ensure that solid benzene deposits could not be formed would impose lower limits on the tank temperature.

\subsubsection{Minimize processing and storage times}

Minimizing the amount of time the precipitate slurry resides at ITP will obviously limit the amount of TPB decomposition and benzene production. Although no specific recommendations are made with respect to processing and storage time reductions, this general recommendation is made here for the sake of completeness.

\subsubsection{Minimize TPB addition}

Minimizing the amount of TPB added to the tank will obviously limit the amount of TPB decomposition and benzene production. Improved liquid phase measurement capabilities (Section 4.4.1) would support this effort.

\subsubsection{Minimize liquid volume}

Minimizing the liquid volume in the tank at any given processing step would minimize the total amount of TPB in solution. Although no specific recommendations are made with respect to liquid volume reductions, this general recommendation is made here for the sake of completeness. It should be noted that a small liquid volume will maximize liquid temperature for a fixed pump heat input, so that the liquid volume may be constrained by the heat removal capability.

\subsection{Reduce Benzene Retention}

This goal concerns the retention of benzene by the precipitate slurry. The only option identified to accomplish this goal would be to increase the frequency and efficiency of agitation. Regardless of the benzene generation rate, large amounts of benzene can accumulate in the precipitate slurry if it is not agitated frequently and effectively. It is prudent to assume that at some point in time a benzene generation rate would be achieved which required that the slurry be mixed at a high frequency over an extended period. It is doubtful that the current pumps could be operated over a long period on such a schedule. Furthermore, it is unknown if the current pumps are capable of effectively mixing the slurry with high liquid volumes. This is particularly true if one or more of the pumps must be taken out of service for maintenance. It is therefore recommended that replacement of the current pumps be considered. If, as assumed here, the current pumps cannot effectively mix the slurry under all conditions on a high frequency schedule over an extended period, then they must be replaced with a system that can accomplish this objective. 


\subsection{Improve Control of Benzene in the Tank Vapor Space}

This goal concerns the retention of benzene by the precipitate slurry. Four approaches are available to achieve the goal of reducing benzene retention:

- improving the mixing behavior of benzene in the vapor space,

- increasing the total tank ventilation rate,

- improving the vapor space measurement capabilities, and/or

- Qualifying the ventilation and purge systems as Safety Class.

Each of these options are discussed separately below.

\subsubsection{Improve vapor space mixing}

All evidence from in-tank testing and tank vapor space mixing CFD (computational fluid dynamics) evaluations indicate that benzene released from the precipitate slurry is relatively well-mixed even at relatively high (few hundred gram per minute) release rates. However, it is recognized that release rates beyond those examined to date could result in poor mixing. It is also recognized that this topic has been of great concern to external regulators, and hence is directly relevant to the perceived risk posed by operations in Tanks 48 and 49. Therefore, it is highly desirable that a serious attempt be made to evaluate the potential for improving the tank vapor space mixing characteristics.

There are a number of potential approaches to improving the tank vapor space mixing characteristics. The CFD evaluations have indicated that several locations near the liquid surface have relatively low velocities (e.g. wake behind the center column and vortex at the center of the circular swirl flow pattern). It is possible that changing the orientation of the nitrogen purge nozzle or employing multiple nozzles may partially mitigate such effects. Such modifications may require that the nitrogen flow rate to the tank be increased (i.e. that additional nitrogen supply lines and storage capacity be added).

Potentially, it may be possible to design an internal re-circulation system that would improve tank vapor space mixing. Conceptually, such a system would draw gas from the tank, compress it, and inject it back into the vapor space at high velocity. Such a system would essentially provide a secondary forced convective mixing source (i.e. in addition to the nitrogen nozzle). This would eliminate the need for additional nitrogen system capacity.

It is recommended that: a) additional CFD evaluations and/or experimental work be undertaken to support the design of an improved nitrogen nozzle set or internal re-circulation system, and b) that the estimate for ITP upgrades include some allowance to support plant modifications in this area.

\subsubsection{Increase ventilation rates}

It is recognized that even with the suggested improvements to decrease the benzene generation and retention characteristics, it is possible that unexpectedly high benzene release rates could still occur at 
some point. It is therefore prudent to ensure that the tank ventilation system is capable of rapidly reducing the bulk vapor space benzene concentration. If air inleakage is reduced to a minimum, then the maximum ventilation rate is constrained by the maximum nitrogen supply rate. As an example, reducing the benzene concentration by a factor of two over the course of one shift ( 8 hours) at a very low liquid volume (100 kgal) with good mixing (mixing efficiency factor of 0.9 ) would require a total ventilation rate of $280 \mathrm{scfm}$. The current nitrogen purge supply system can supply nitrogen at double this flow rate. Hence, significant increases in the ventilation rate are probably not required to ensure that the vapor space benzene concentration can be reduced in a timely fashion.

It would also be prudent to ensure that the tank ventilation system is capable of supporting an extended release at a moderately high rate [in addition to ensuring that the tank vapor space is well-mixed in such a case (Section 4.3.1)]. Given the recommendations provided in Sections 4.1 and 4.2, it is reasonable to assume that a sustained release rate of $100 \mathrm{~g} / \mathrm{min}$. is a reasonable target. Maintaining the vapor space benzene concentration to $10 \%$ of its LFL (i.e. $0.137 \%$ ) at this release rate and a vapor space temperature of $25^{\circ} \mathrm{C}$ would require a total ventilation rate of $810 \mathrm{scfm}$. Since reducing the air inleakage rate to a minimum will reduce the ventilation rate to near the purge supply rate, the current purge supply rate should be configured to supply at least $800 \mathrm{scfm}$. Note that it is not anticipated that this flow rate would be required under most conditions.

It is recognized that it is possible that release rates even higher than those assumed above could occur. It is therefore recommended that the tanks be equipped with auxiliary purge and ventilation capability. Portable ventilators could supply auxiliary ventilation capability. Auxiliary purge capability could be supplied with an additional purge supply line and associated storage capability. Note that these systems would not be used during normal operations, but would be available to mitigate higher than expected release rates over an extended period. It is judged that it is not necessary to increase the capacity of the normal systems to cover this contingency.

\subsubsection{Improve vapor space measurement capabilities}

It is recognized, of course, that improving the capability to measure benzene concentration distributions in the tank vapor space will not actually improve the tank mixing behavior. However, improved measurement capabilities would provide more timely detection of an elevated benzene release rate and would support more meaningful analysis of the potential for significant concentration gradients. The facility had initiated design efforts for a set of two axial sampling arrays to measure both oxygen and benzene concentrations. These design efforts should be completed. 


\subsubsection{Qualify ventilation and purge systems as $S C$}

The tank ventilation and/or purge systems occasionally fail and are not NPH qualified. The shutdown of these systems is highly undesirable since it necessitates that processing be stopped and can trigger activation of the backup purge system. An extended duration without ventilation would lead to increasing the benzene inventory in the liquid phase and, eventually, elevated tank vapor space benzene concentrations. In addition to the negative impact on fuel control during this period, these conditions would complicate a return to normal operations. Ensuring that the ventilation and purge systems are available at all times by making the design changes required to qualify them as Safety Class would therefore be highly desirable. However, given the reliance on inerting and qualification of the backup purge system, such modifications are not a necessity.

It was recommended in Section 3.1.1 that the cost and schedule requirements associated with this option be estimated and compared with the alternative options for reducing air inleakage during a loss of purge. It is anticipated that the requirements would be unfavorable. However, if this is not the case, then this approach would have benefits for this issue as well.

\subsection{Improve Process Knowledge to Facilitate Controls}

This goal concerns improving the level of process knowledge in order to facilitate the application of appropriate operational controls. The confidence level associated with fuel control could be increased if the measurement capabilities associated with the process were improved. This is applicable to both liquid- and vapor-phase measurements. Each of these areas are discussed below.

\subsubsection{Improve Liquid-Phase Measurement Capabilities}

It would be prudent to put into place measurement capabilities that would support frequent sampling of the liquid phase. In addition, the samples should be obtained in a manner that allows reasonably accurate determination of the concentrations of all chemical species relevant to benzene production (i.e. TPB, its decomposition products, and benzene) and the parameters selected to control benzene and hydrogen production (i.e. inhibitor species). The design and deployment of a system meeting these requirements is recommended.

\subsubsection{Improve Vapor-Phase Measurement Capabilities}

It would be prudent to put into place system measurement capabilities that would support benzene concentration measurements at a number of locations within the tank vapor space. Coupled with the liquid-phase measurements, this would provide a definitive picture of the effectiveness of the benzene generation, retention, and release controls. Note that enhanced vapor-phase measurements were previously recommended in connection with improving the control of benzene in the tank vapor space (Section 4.3) and with increasing the confidence level associated with elevated oxygen concentration 
regions (Section 4.5). As in these earlier sections, it is recommended here that the initial design efforts in this area be carried forward to completion. 


\subsection{PRODUCTION GOALS (TANKS 48 \& 49)}

The options available to increase the reliability of fuel control via reductions in the benzene generation rate (Section 4.1) are all directly applicable to reducing the rate of solids decomposition, and hence to increasing the likelihood that HLW processing production goals will be met. The recommendations given in Section 4.1 are therefore directly applicable here. 


\subsection{RECOMMENDED OPTION SET (TANKS 48 \& 49)}

The set of options recommended in Sections 4 through 6 with respect to oxidant control, fuel control and production goals are summarized in Table 3. As noted in the Introduction, the intent of this report is to provide relatively broad recommendations. It is expected that, if modifying the current ITP facility was selected as the best path forward, then the general recommendations provided in this report would be utilized to develop a set of detailed recommendations, which would then be followed by specific implementation plans. 


\subsection{OTHER ITP INSTALLATIONS}

\subsection{Tank 50}

The enhanced liquid- and vapor-phase measurement capabilities added to Tanks 48 and 49 should be replicated in Tank 50. The same need for an accurate assessment of the state of TPB decomposition and benzene generation, retention, and release mechanisms are needed for Tank 50 , and hence the same type of measurement capabilities are recommended.

Tank 50 is an air-based tank that does not currently employ inerting. Air-based ventilation can be employed with Tank 50 because this tank receives only spent wash water and the expected benzene release rates are quite low. However, this complete reliance on fuel control is difficult to support at the current time given the uncertainties in benzene generation (even in the wash water). It is therefore recommended that Tank 50 be supplied with a nitrogen purge. It is possible that a combination of modeling and enhanced measurement capabilities (liquid-and vapor-phase) would allow Tank 50 to be kept in an air-based mode for most of the time, but the capacity to inert the vapor space should be made available if in-tank measurements signal an increasing benzene generation rate, inventory, or release rate.

The Tank 50 cooling capacity might not have to be upgraded to maintain a low liquid temperature since the frequency of agitation required in this tank can be much lower than in Tanks 48 and 49 (i.e. Tank 50 will not contain only liquid and hence poses a much smaller benzene depletion challenge). However, upgrading the Tank 50 cooling capacity to match that in Tanks 48 and 49 is desirable to provide increased operational flexibility, and is therefore recommended.

\subsection{Filtrate Hold Tanks}

It is recommended that the Filtrate Hold Tanks be supplied with a cooling system capable of maintaining the same temperature limits adopted for Tank 48. The FHTs already employ nitrogen inerting. The FHT inerting system should be reviewed to ensure it is sufficiently robust. 


\subsection{RELATED FACILITIES}

As noted in Section 1, potential modifications to associated facilities (Saltstone, Late Wash, and the Low Point Pump Pit) are considered beyond the scope of this work. However, the need for such modifications to support continued precipitation operations at the current ITP facility should be clearly noted.

The Saltstone facility receives decontaminated filtrate from Tank 48. The receipt and processing tanks are ventilated with air, and the ventilation system design and qualification is predicated on a low benzene generation rate. It is doubtful that the assumed rate can be ensured with near $100 \%$ confidence for all future operations. The ventilation system will therefore probably need to be upgraded and, potentially, the tanks may require inerting.

The Late Wash Facility receives precipitate slurry from ITP and performs a secondary wash and precipitation step. Increased benzene generation and release rates beyond the design basis for this facility will drive some level of design modifications to the ventilation and purge systems to ensure an acceptable level of vapor space flammability control.

The Low Pump Pit receives precipitate slurry from Late Wash and sends it on to the DWPF Vitrification Facility. As with Late Wash, increased benzene generation and release rates beyond the design basis for this facility will drive some level of design modifications to the ventilation and purge systems to ensure an acceptable level of vapor space flammability control.

The total cost for the design modifications required allow continued precipitation operations at the current ITP facility should include some contingency to cover design modifications at these related facilities. 


\subsection{CONCLUSIONS}

The purpose of this evaluation was to generate a set of recommended design modifications and operational approaches that would allow continued precipitation operations at the current ITP facility. These recommendations are intended to be general rather than specific in nature.

The approach adopted in this evaluation was to collect the options available for decreasing the risk posed by vapor space flammability issues and increasing the confidence level that production goals can be met, and then qualitatively rank these options with respect to their potential for meeting these objectives. The most effective options were then selected as the set of recommended design modifications and operational approaches. In this context, the determination that an option is "effective" is meant to convey both that the option will be effective in terms of meeting a specific goal and it is expected that the option will be effective in terms of its relative order-of-magnitude cost. Some of the options that would act to improve oxidant control would also improve fuel control, and some of the options that would act to improve fuel control would also improve process viability. Options which contribute simultaneously to improved oxidant control, fuel control, and process viability, have an obvious attraction. The recommended set of design modifications and operational approaches are summarized in Table 3.

It should be clearly understood that meeting the safety requirements for HLW processing involves more than simply meeting the DOE Evaluation Guidelines. External reviewers must be satisfied that the risk posed by vapor space flammability issues is acceptable. Unfortunately, the term "acceptable risk" is difficult to precisely define. It is, in a very real sense, defined by what level of risk external regulatory authorities will be willing to accept in order to process HLW. As such, the selection of a safety strategy that will result in an "acceptable risk" is very much an exercise in judgement. Similarly, uncertainties in precipitate decomposition kinetic preclude complete assurance that production goals will be met regardless of potential facility modifications. Hence, while it is the judgement of the author that adopting the recommendations provided in this report would provide a high level of assurance that the HLW processing production goals and safety requirements could be met, this outcome is not guaranteed. 
WSRC-RP-98-00735

Page 25 of 27

10.0 REFERENCES

Jacobs, R.A., J.R. Fowler, and P.L. Rutland (1998) "Summary of the In-Tank Precipitation Chemistry Program," WSRC-RP-98-00300, Savannah River Site, Aiken, SC, 7/14/98.

Thomas, J.K. (1996a) "Composite Minimum Oxygen Concentration for Benzene-Hydrogen-Nitrogen-Air Mixtures," Technical Report WSRC-RP-96-619, Savannah River Site, Aiken, SC, 12/96.

Thomas, J.K. (1996b) "Impact of Hydrogen on the Formation of Flammable Mixtures in Tank 48 During PVT-1 Operations," Calculation Note M-CLC-H-01367 (rev.0), 12/96.

Thomas, J.K. (1997a) "Effect of Low Flow Nitrogen Purge on Tank 48 Bulk Oxygen Concentration," Calculation Note M-CLC-H-01451 (rev.0), 10/97.

Thomas, J.K. (1997b) "Time Required for the Bulk Oxygen Concentration to Reach the CMOC in Tank 48," Calculation Note M-CLC-H-01450 (rev.0), $10 / 97$.

Whittenburg, A.L. (1998) "HLW Salt Disposition Alternatives Identification - Preconceptual Phase II Summary Report,” WSRC-RP-98-00165, Savannah River Site, Aiken, SC, 6/27/98. 
Table 1 Options Considered for Improved Fuel Control in Tanks 48 and 49.

\begin{tabular}{|ll|l|}
\hline \multicolumn{1}{|c|}{ Goal } & \multicolumn{1}{c|}{ Option } \\
\hline $\begin{array}{l}1 \text { Reduce Precipitate Decomposition and Benzene } \\
\text { Generation Rates }\end{array}$ & $\begin{array}{l}\text { a) Pretreat for catalyst removal and/or deactivation } \\
\text { b) Reduce liquid phase temperature } \\
\text { c) Minimize processing and storage times } \\
\text { d) Minimize TPB addition } \\
\text { e) Minimize liquid volume }\end{array}$ \\
\hline 2 Reduce Benzene Retention & a) Increase agitation frequency and effectiveness \\
\hline 3 Improve Control of Benzene in Tank Vapor Space & $\begin{array}{l}\text { a) Improve vapor space mixing } \\
\text { b) Increase ventilation and purge rates } \\
\text { c) Improve vapor space measurement capabilities } \\
\text { d) Qualify ventilation and purge systems as SC }\end{array}$ \\
\hline 4 Improve Process Knowledge to Facilitate & $\begin{array}{l}\text { a) Improve liquid phase measurement capabilities } \\
\text { b) Improve vapor space measurement capabilities }\end{array}$ \\
\hline
\end{tabular}

Table 2 Options Considered for Improved Oxidant Control in Tanks 48 and 49.

\begin{tabular}{|ll|l|}
\hline \multicolumn{1}{|c|}{ Goal } & \multicolumn{1}{c|}{ Option } \\
\hline 1 Eliminate Air Inleakage During Normal Operation & a) Utilize positive pressure inerting system \\
\hline 2 Reduce Air Inleakage During Normal Operation & $\begin{array}{l}\text { a) Decrease tank vacuum } \\
\text { b) Improve tank vapor space seal } \\
\text { c) Reduce routine tank vapor space breaches }\end{array}$ \\
\hline 3 Reduce Air Inleakage During a Loss of Purge & $\begin{array}{l}\text { a) Eliminate loss of purge (qualify ventilation and } \\
\text { purge systems as SC) [*] } \\
\text { b) Improve vapor space isolation upon loss of purge } \\
\text { c) Improve tank vapor space seal (see goal \#2) } \\
\text { d) Reduce tank vapor space temperature [*] } \\
\text { e) NPH qualified vapor space boundary }\end{array}$ \\
\hline 4 Improve Backup Positive Pressure Inerting System & $\begin{array}{l}\text { a) See list of options given for goal \#3 } \\
\text { b) Improve system control scheme }\end{array}$ \\
\hline 5 Performance & $\begin{array}{l}\text { a) Reduce air inleakage (see options for goals \#2-\#4) } \\
\text { b) Improve vapor space mixing [*] }\end{array}$ \\
\hline 6 Increase Ability to Preserve CMOC & $\begin{array}{l}\text { c) Improve vapor space measurement capabilities } \\
\text { c) Reduce } \mathrm{O}_{2} \text { conc. below minimum CMOC } \\
\text { d) Increase agitation frequency \& effectiveness [*] }\end{array}$ \\
\hline
\end{tabular}

[*] denotes option also considered to improve fuel control (see Table 1). 
Table 3 Summary of Recommendations for Tanks 48 and 49.

\begin{tabular}{|c|c|c|}
\hline Recommendation & Section & Comments \\
\hline Decrease tank vacuum & 3.2 .1 & reduce air inleakage \\
\hline Improve tank vapor space seal & $3.2 .2,3.3 .3$ & reduce air inleakage \\
\hline Reduce routine tank vapor space breaches & 3.2 .3 & reduce air inleakage \\
\hline $\begin{array}{l}\text { Estimate costs associated with qualifying } \\
\text { ventilation and purge systems as Safety Class }\end{array}$ & $3.3 .1 \& 4.3 .4$ & $\begin{array}{l}\text { not expected to be cost- } \\
\text { effective }\end{array}$ \\
\hline $\begin{array}{l}\text { Improve vapor space isolation upon loss of } \\
\text { purge }\end{array}$ & 3.3 .2 & reduce air inleakage \\
\hline Reduce tank vapor space temperature & 3.3 .4 & to $\leq 25^{\circ} \mathrm{C}$, limit air inleakage \\
\hline Improve backup inerting system control scheme & 3.4 & nitrogen conservation \\
\hline Improve vapor space measurement capabilities & $\begin{array}{l}3.5 .2,4.3 .3 \& \\
4.4 .2\end{array}$ & \\
\hline $\begin{array}{l}\text { Reduce oxygen concentration below the } \\
\text { minimum CMOC }\end{array}$ & 3.6 .1 & $\begin{array}{l}\text { via tank vacuum \& seal } \\
\text { improvements }\end{array}$ \\
\hline Increase agitation frequency \& effectiveness & $3.6 .2 \& 4.2$ & oxidant \& fuel control \\
\hline Pretreat for catalyst removal and/or deactivation & 4.1 .1 & \\
\hline Reduce liquid phase temperature & 4.1 .2 & to $\leq 25^{\circ} \mathrm{C}$ \\
\hline Minimize processing and storage times & 4.1 .3 & no explicit guidance offered \\
\hline Minimize TPB addition & 4.1 .4 & no explicit guidance offered \\
\hline Minimize liquid volume & 4.1.5 & no explicit guidance offered \\
\hline Improve vapor space mixing & 4.3 .1 & benzene control \\
\hline Increase ventilation and purge rates & 4.3 .2 & auxiliary capacity \\
\hline Improve liquid phase measurement capabilities & 4.4 .1 & \\
\hline
\end{tabular}

